\title{
Electrically injected InP microdisk lasers integrated with nanophotonic SOI circuits
}

\author{
J. Van Campenhout ${ }^{1 *}$, P. Rojo-Romeo ${ }^{2}$, P. Regreny ${ }^{2}$, C. Seassal ${ }^{2}$, D. Van Thourhout ${ }^{1}$, L. Di

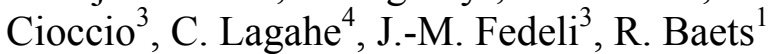 \\ ${ }^{1}$ Ghent University-IMEC, Sint-Pietersnieuwstraat 41, 9000 Ghent, Belgium \\ ${ }^{2}$ Institut des Nanotechnologies de Lyon (INL), France, ${ }^{3}$ CEA-DRT/LETI, France, \\ ${ }^{4}$ Tracit Technologies, France
}

\begin{abstract}
We have achieved continuous-wave electrically-injected lasing operation at room-temperature in InP-based microdisks heterogeneously integrated on a SOI nanophotonic circuit. The microdisks were evanescently coupled with sub-micron SOI wire waveguides, resulting in up to $10 \mu \mathrm{W}$ waveguide-coupled unidirectional output power, with a measured slope efficiency up to $20 \mu \mathrm{W} / \mathrm{mA}$. A tunnel junction was used for efficient electrical injection with low optical absorption. The measured laser performance agrees well with calculations based on a standard laser model. This model suggests that considerable improvement in laser performance is possible.
\end{abstract}

Keywords: microdisk laser, heterogeneous integration, silicon photonics

\section{INTRODUCTION}

Silicon-on-insulator (SOI) has emerged as a promising platform to achieve compact nanophotonic ICs, due to the transparency of silicon at telecom wavelengths, its high refractive index contrast and the fact that CMOS processing infrastructure can be used for fabrication [1]. A major obstacle for large-scale silicon-based electronic-photonic integration is the absence of a compact and efficient silicon-based light source, due to the indirect band gap of silicon. Despite some recent encouraging results, compact and efficient electrically pumped silicon-based lasers don't seem feasible in the short term. An alternative approach to add efficient active photonic functionality to the SOI platform is through heterogeneous integration of a thin III-V epitaxial film using bonding technology. Since the processing of the III-V layers can be done after bonding, the critical alignment to the underlying SOI waveguides is obtained through lithography, as opposed to flip-chip approaches. Over the last twenty years, microdisk lasers have shown good potential as compact and coherent light sources for large-scale photonic integrated circuits [2,3]. These microdisk structures support whispering-gallery resonances that enable ultra-compact and low-threshold laser operation. Electrically-injected microdisk lasers have been demonstrated on InP substrates with threshold currents as low as $40 \mu \mathrm{A}$ [4]. In this work, we have used heterogeneous bonding technology to integrate electrically-injected InP microdisk lasers on a SOI nanophotonic waveguide platform.

\section{MICRODISK LASER DESIGN}

A schematic drawing of the laser structure is shown in figure 1. A microdisk is etched in the InP-based layer, leaving a thin lateral bottom layer. The fundamental optical resonances in such a structure are whispering gallery modes (WGMs), which are confined to the edges of the microdisk. Therefore, a top metal contact can be placed in the center of the microdisk, without adding extra optical losses. The bottom contact is positioned on a thin lateral contact layer: this layer will cause no substantial additional optical losses, provided it is sufficiently thin. The laser resonance is evanescently coupled to the underlying SOI waveguide, which is vertically aligned with the edge of microdisk.

* joris.vancampenhout@intec.ugent.be

Silicon Photonics III, edited by Joel A. Kubby, Graham T. Reed

Proc. of SPIE Vol. 6898, 68980L, (2008) $\cdot 0277-786$ X/08/\$18 $\cdot$ doi: 10.1117/12.767958

Proc. of SPIE Vol. 6898 68980L-1 


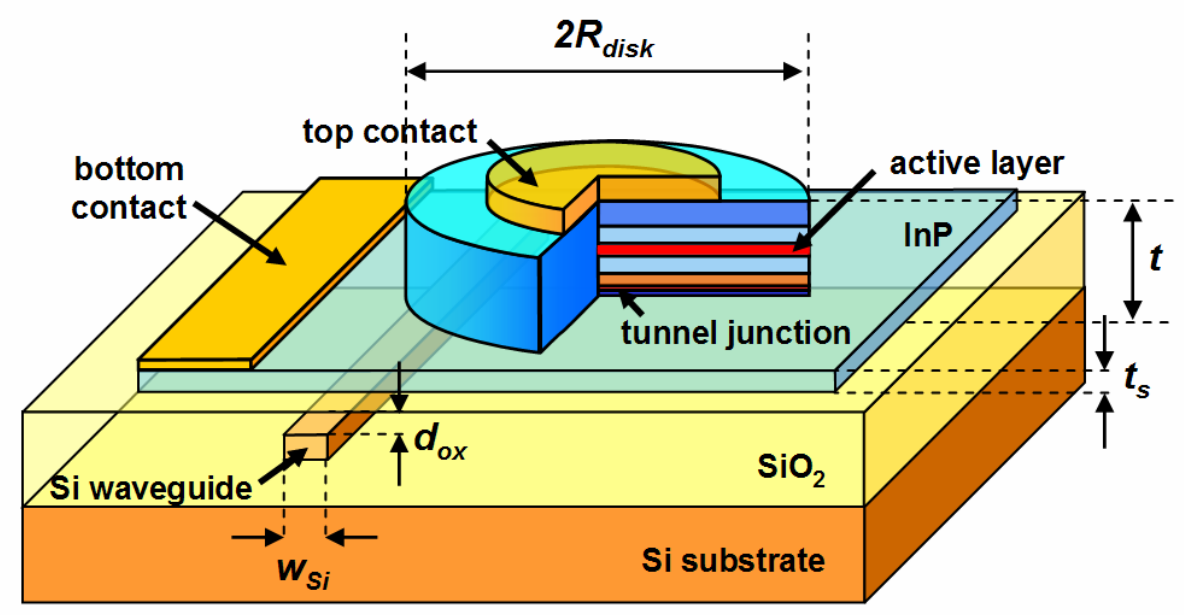

Figure 1. Schematic representation of the heterogeneously integrated microdisk laser

An important design aspect is the composition of the bonded InP-based film. It should enable efficient current injection, while preserving the optical resonance quality. The epitaxial layer should also be as thin as possible, since optical coupling to the underlying SOI waveguide is expected to be less efficient for thicker InP films. Thicker devices are also more difficult to etch with low surface roughness and to planarize, thus making integration more difficult. The major challenge in the epitaxial design lies in the requirement for low-voltage operation and high injection efficiency together with low internal optical loss. A major bottleneck for the electrical current could occur at the p-type contact. It is known that it is much more difficult to achieve low-resistance metal contacts to p-type $\mathrm{InP}$ as compared to n-type InP. In traditional InP-substrate based lasers, this is solved by using heavily p-type doped, low bandgap contact layers such as $\mathrm{p}++$ InGaAs. These layers have large optical absorption, due to band-to-band absorption and/or free-carrier absorption (FCA), as highly p-type doped layers have large intervalence band absorption (IVBA). In classic substrate lasers, relatively thick $(>1 \mu \mathrm{m})$ cladding layers provide optical isolation between the waveguide core and these very absorptive contact layers. In our approach, a tunnel junction is incorporated to efficiently contact the p-type diode layer, with low optical loss. As has been shown in the case of long-wavelength vertical-cavity surface-emitting lasers (VCSELs), TJs with a bandgap wavelength above the emission wavelength exhibit relatively low electrical resistance with only a minor optical loss penalty, provided that the TJ is well-positioned at a minimum of the optical field intensity and has adequate doping levels [5]. In our design, we have used a Q1.2 tunnel junction. While this approach outperforms a design based on a ternary p++ InGaAs contact layer, the major contribution to the internal loss is still due to free-carrier related losses in the heavily doped TJ layers. Therefore, the doping level of the TJ layers is an important design parameter, which allows for a trade-off between low optical losses and low electrical resistance.

Further contributions to the optical loss in the resonator are bending losses, scattering losses and coupling loss to the SOI wire waveguide. Numerical simulations indicate that the microdisk - including the bottom contact layer - can be as small as $4.5 \mu \mathrm{m}$ in diameter before bending losses become important. Scattering losses arise due to sidewall roughness, and can thus be strongly reduced by optimizing the dry etch processes used for obtaining the microdisk shape. Finally, the coupling loss to the SOI wire depends strongly on the thickness of the bonding layer, and should be optimized for obtaining optimum laser performance. A useful rule of thumb is to make the coupling loss equal to the parasitic loss. Numerical simulations (3-D FDTD) indicate that this can be achieved by bonding layer thicknesses in the range 100$200 \mathrm{~nm}$, for microdisk thicknesses in the range $1-0.5 \mu \mathrm{m}$. For further details on the modeling, we refer to [6]

\section{EXPERIMENTAL RESULTS}

We have fabricated SOI-integrated microdisk lasers, both in $0.55-\mu \mathrm{m}$ thick and $1-\mu \mathrm{m}$ thick bonded epitaxial structures., as illustrated in . For fabrication details, we refer to [7]. The microdisk diameters were $5 \mu \mathrm{m}, 7.5 \mu \mathrm{m}$ and $10 \mu \mathrm{m}$. Before 
(a)

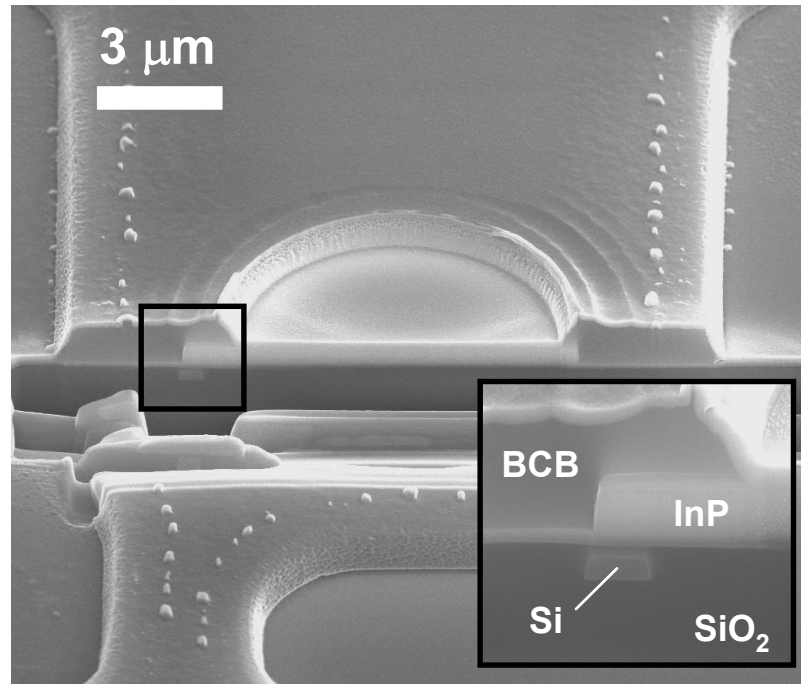

(b)

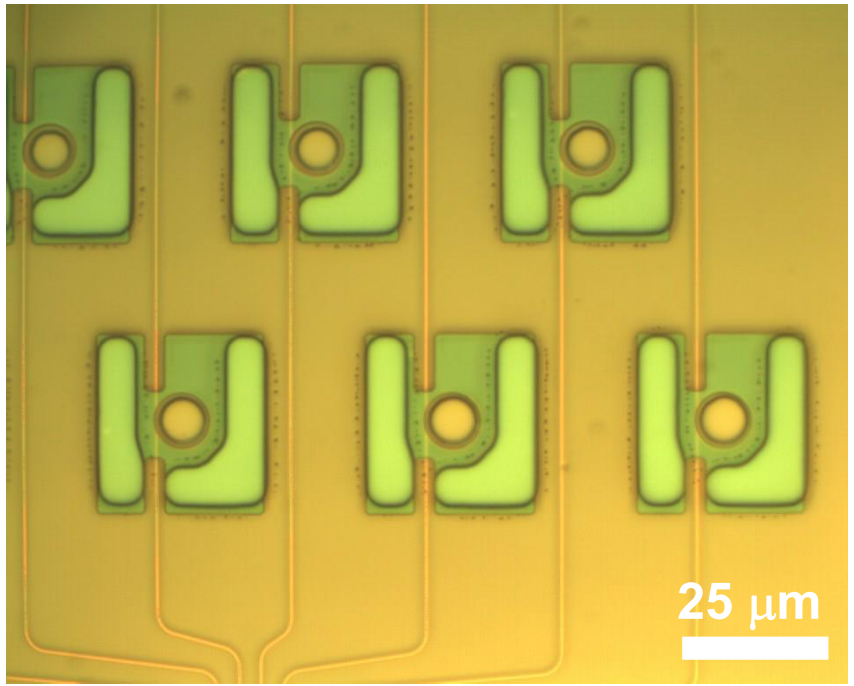

Figure 2. (a) FIB/SEM image in cross section of microdisk laser before metallization. (b) Top down microscope image of 6 microdisk lasers on SOI.

(a)

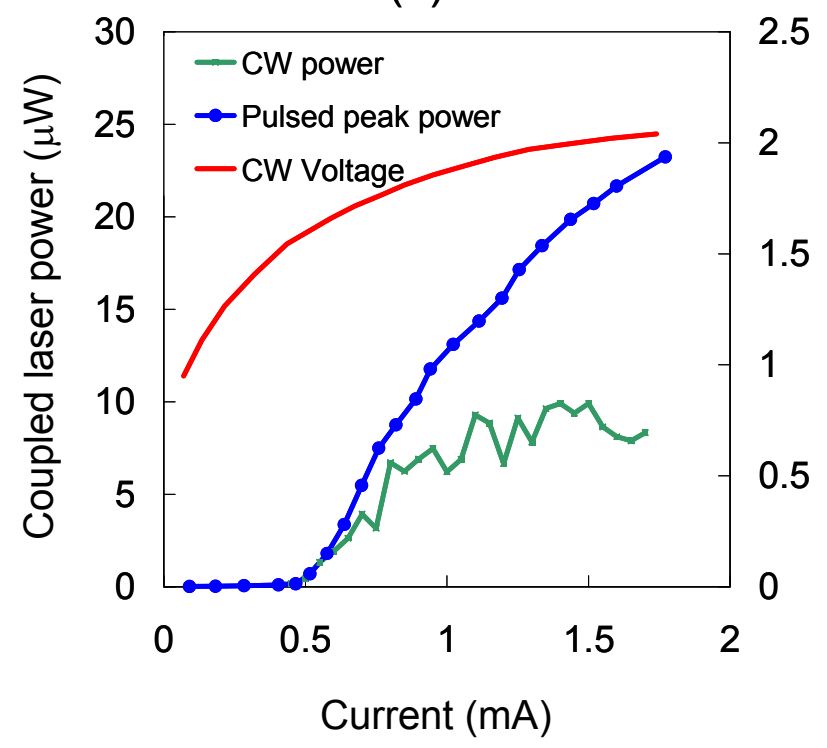

(b)

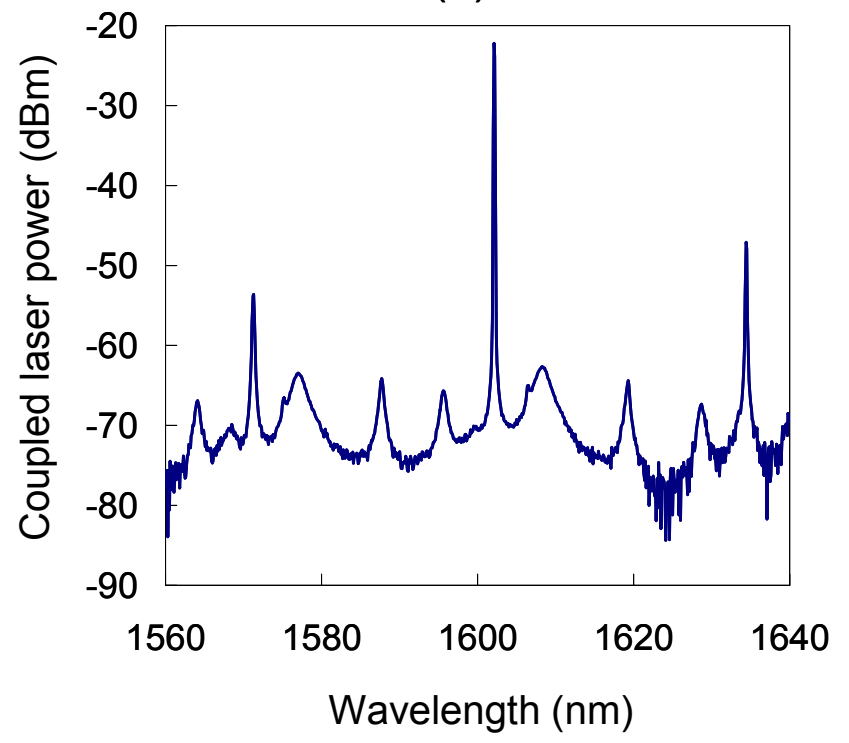

Figure 3. (a) L-V-I data measured for a 7.5-mm microdisk laser. (b) Lasing spectrum for 1.4mA current injection.

metallization, the microdisk lasers were tested under optical pumping, and all devices exhibited lasing with sub-mW threshold powers and substantial coupling into the SOI waveguide. After BCB processing and metallization and a burnin treatment, electrically pumped characterization was performed. Devices with variable top contact size $(0.7-0.84 \mathrm{R})$ were available, and lasing performance was found to depend strongly on the size and position of the top contact. During fabrication, the top contact was misaligned by $400 \mathrm{~nm}$. As a result, lasing from $5 \mu \mathrm{m}$-diameter microdisks was generally poor. The measured lasing characteristics for a $7.5-\mu \mathrm{m}$ microdisk are shown in fig. 3. Lasing was obtained at room temperature both in pulsed and continuous wave $(\mathrm{CW})$ regime. The best lasers had a threshold current of $0.5 \mathrm{~mA}$ and a differential efficiency of about $30 \mu \mathrm{W} / \mathrm{mA}$ in pulsed regime, with up to $100 \mathrm{~mW}$ peak output power. In $\mathrm{CW}$, the output 
(a)

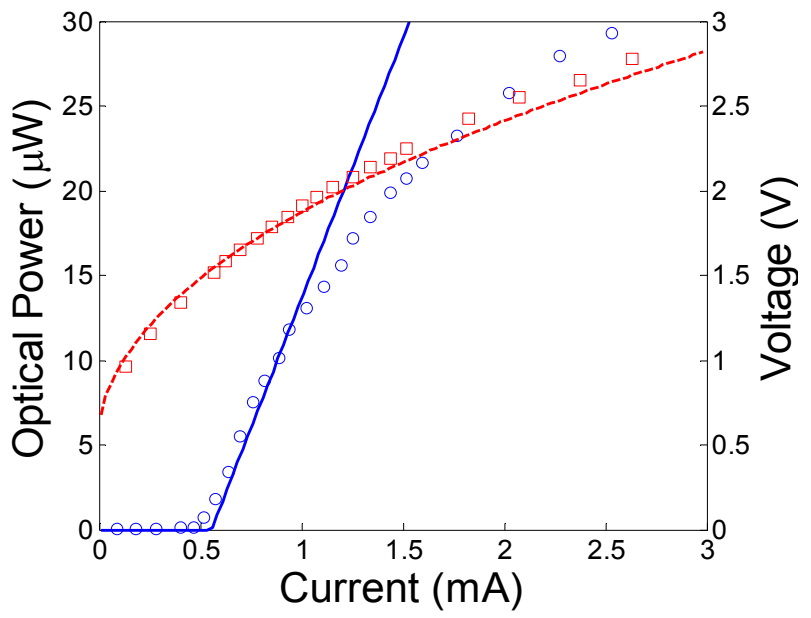

(b)

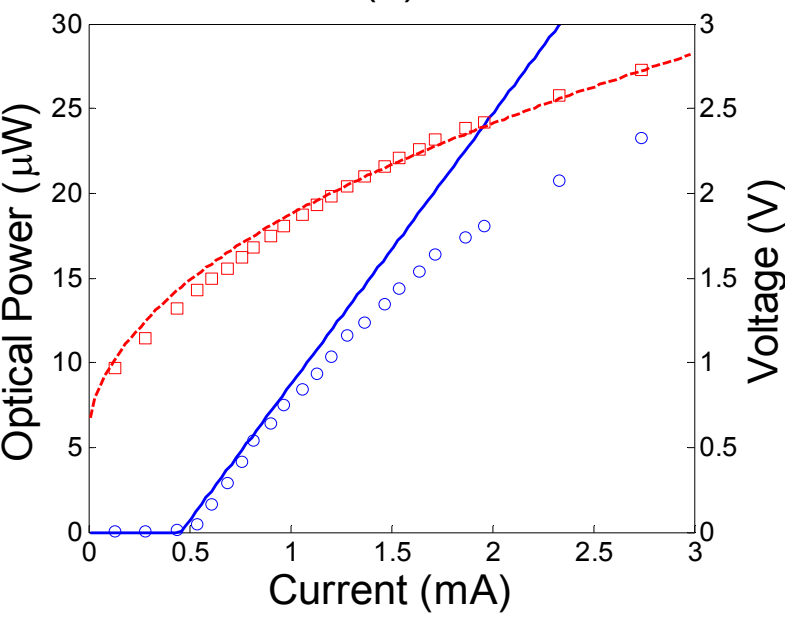

Figure 4. Measured (markers) and fitted (lines) lasing performance in pulsed regime for two 7.5- $\mu \mathrm{m}$ microdisk lasers with different coupling loss.

power was limited to about $10 \mu \mathrm{W}$ due to early thermal roll-over. The device voltage was below $2 \mathrm{~V}$. The lasing spectrum, as shown in fig 3. (b) exhibited a clear single lasing peak at $1.6 \mu \mathrm{m}$, with a linewidth that was equal to or smaller than the resolution of our measurement setup $(60 \mathrm{pm})$.

\section{DEVICE OPTIMIZATION}

A theoretical lasing model, based on classical laser theory applied to the microdisk laser configuration, and including a theoretical electrical TJ model from literature, was used for the interpretation of the measurement results (in pulsed regime). A good fit could be obtained using model parameter values obtained from simulations as discussed in section 2, and assuming reasonable values for parameters that couldn't be estimated through simulation. This is illustrated in fig. 4, where the experimental data is compared with the theoretical fit, for two $7.5-\mu \mathrm{m}$ microdisk lasers with different lateral waveguide-disk offsets. Good agreement was obtained both for the output power as for the device voltage, except for the saturation of the output power at higher pumping levels.

To estimate the performance of a fully optimized microdisk structure, the theoretical model was used to find the optimum values for the dominant design parameters, which were identified as the microdisk radius, p-type doping of the TJ and the coupling loss. These calculations indicate that a fully optimized microdisk laser could reach a wall-plug efficiency of more than $10 \%$.

\section{CONCLUSION}

We have developed an electrically-injected InP-based microdisk laser, integrated on and coupled to a nanophotonic SOI platform. Electrically injected lasing in continuous-wave regime was obtained at room temperature, with lasing thresholds around $0.5 \mathrm{~mA}$, device voltages below $2 \mathrm{~V}$, and slope efficiencies up to $30 \mu \mathrm{W} / \mathrm{mA}$. The measured lasing performance could be fitted by a theoretical model using model parameter values obtained from simulation. This model predicts a wall-plug efficiency of over $10 \%$ for a fully optimized microdisk structure. 


\section{REFERENCES}

1 W. Bogaerts, R. Baets, P. Dumon, V. Wiaux, S. Beckx, D. Taillaert, B. Luyssaert, J. Van Campenhout, P. Bienstman, D. Van Thourhout, "Nanophotonic waveguides in silicon-on-insulator fabricated with CMOS technology," IEEE J. of Lightwave Technol. 23, 401-412, (2005).

2 A. F. J. Levi, R. E. Slusher, S. L. Mccall, T. Tanbunek, D. L. Coblentz, and S. J. Pearton, "Room-temperature operation of microdisk lasers with submilliamp threshold current," Electronics Letters, vol. 28, no. 11, pp. 1010-1012, 1992.

3 T. Baba, M. Fujita, A. Sakai, M. Kihara, and R. Watanabe, "Lasing characteristics of GaInAsP-InP strained

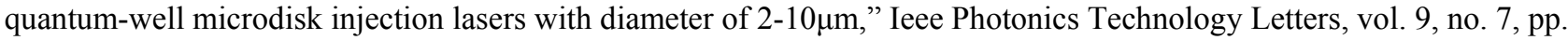
878-880, 1997.

4 M. Fujita, R. Ushigome, and T. Baba, "Continuous wave lasing in GaInAsP microdisk injection laser with threshold current of 40 ua," Electronics Letters, vol. 36, no. 9, pp. 790-791, 2000.

5 J. Boucart, C. Starck, F. Gaborit, A. Plais, N. Bouche, E. Derouin, J. C. Remy, J. Bonnet-Gamard, L. Goldstein, C. Fortin, D. Carpentier, P. Salet, F. Brillouet, and J. Jacquet, "Metamorphic dbr and tunneljunction injection: A cw rt monolithic long-wavelength vcsel," IEEE Journal of Selected Topics in Quantum Electronics, vol. 5, no. 3, pp. 520-529, 1999.

6 J. Van Campenhout, P. Rojo-Romeo, D. Van Thourhout, C. Seassal, P. Regreny, L. Di Cioccio, J. M. Fedeli, C. Lagahe, and R. Baets, "Electrically pumped inp-based microdisk lasers integrated with a nanophotonic silicon-oninsulator waveguide circuit," Optics Express, vol. 15, no. 11, pp. 6744-6749, 2007.

J. Van Campenhout, P. Rojo-Romeo, D. Van Thourhout, C. Seassal, P. Regreny, L. Di Cioccio, J. M. Fedeli, and R. Baets. Design and Optimization of Electrically Injected InP-based Microdisk Lasers Integrated on and Coupled to a SOI Waveguide Circuit. Journal of Lightwave Technology, to be published. 
SESSION 5

Room: Conv. Ctr. A1 ................. Tues. 1:30 10 $3: 30 \mathrm{pm}$ Silicon Photonics !

Sesson Chair Phippe M. Fauchet, Unv. of Rochester

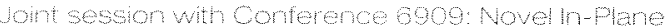
Semooncturt asers

$130 \mathrm{pm}$ : A monolithic integrated low threshold Aaman siticon laser Imvited

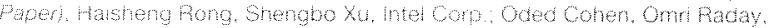

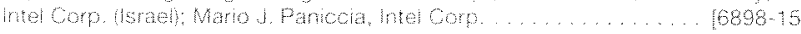

200 prn: Silcon nanocrystals and Er coupled to silicon nanocrystals for lasers and amplifiers hmited Paper Noon Daldosso, Lorenzo Pavesi zano Gaburo. Lrw degl Stud di Tento (tany) . . . . . . . . . . . . . . 16898-16

$2.30 \mathrm{pm}$ Monohhicaly integrated 11.56 diode lasers on miscut $\mathrm{S}$ substrates (mwted Paper, Diana L. Huffaker. Ganesh Balakrishnan, Unv, of CalifornaLLs Angetes; A. Jallipath, M. N. Kuty, S. tuang, Larry R. Dawson, The

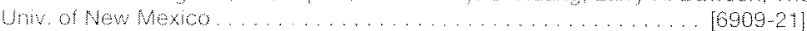

300 pm: on-chip integration of quantum dot lasers with waveguides and modulators on Si invted Papen. Pallab K. Bhatacharya, Jun Yang, Univ of Michigan $16909-22$

Coltee Break $3: 30$ to $4: 00 \mathrm{pm}$

\section{SESSION 6}

Room: Conv. Ctr. A1 ................... Tues, 4:00 to 5:30 pm

Silicon Photonics II

Session Chair: Mario J. Paniccia, Intel Corp

Join session with Conference 6009

Novel in-Pane Seniconductor Lasers VII

400 pm: Electrically injected inf microdisk lasers integrated with nanophotonic Sol circuits invited Paper. Uors Van Campenhout, Univ. Gent Qelgum: Pedro Rojo-Romeo, Phitippe Regreny. Cmmstim Seassat, Ecole Centrate de Lyon fFrance); Ones Van Thourhout Univ. Gent (Beloium); Lea

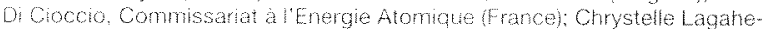
Banchard. TRACT Technologies (fFance); Jegn Mare Fedeli Commissariat a PEergle Atomgue (France): Poel G. Qaets, Unw. Gent (Betgum)... [6898-17] 4,30 ph: Recess integration of micro-cleaved laser diode platelets wiltr dielectric waveguides on sificon (lowiteg Paper), Chifton G. Fonstad. ir. Joseph Rumpler. Ecwari Barkey, Shava Famenini James Perkins. Massachusets institute of Techology. ............. $6909-23$ $500 \mathrm{pm}$ integrated AlGanAs-silicon evanescent racetrack laser and photodevector Invited Papen, Alexander W. Fang, Unik of Califomia/Sant Barbara; Pichard Jones. Intel Comp. Hyundas Park. Univ of Callomia/Santa Earbara: Oded Cohen, Omrn Raday, Intel Corp. (sraeli; Mario J. Paniccia, Intel

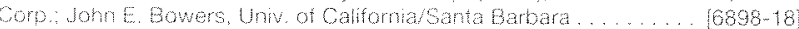

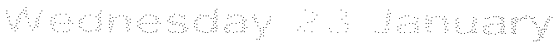

\section{SESSION ?}

Room: Conv. Gr. A1 ................Wed 8:10 to 10:10 am

Waveguides!

Session Chair: Andrew W. Poon, Hong Kong Unw. of Scignce and Technology (Hong Kong China)

8.0 an: Srategies for sealization of strong contmement microphotonic

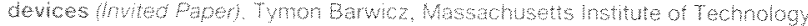

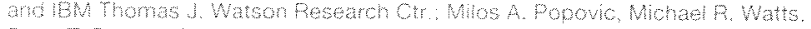

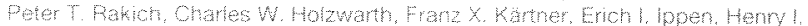
Smith Massachusets Instute of Technolon. ................ [6898-19] $860 \mathrm{~mm}$ Segmented and slotted waveguties for high speed electro-optic

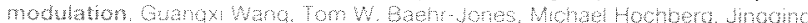

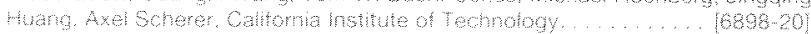

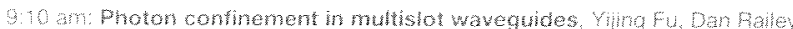

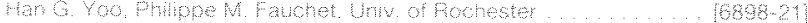

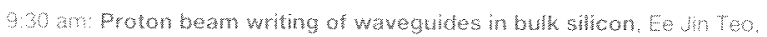

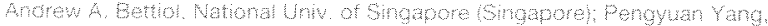

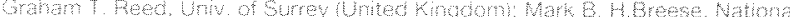

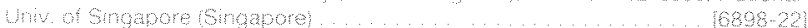

950 an: Submicron optical waveguides for sificon photonics formed via the focal oxidation of silicon (LOCOST. Frederic Y. Gardes. Graham T. Feed Univ of Surrev United Knodom: Andrew P. Knights. Mchaster Univ Canada: Goran Z. Mashahovich, David Thomson, Unv of Surrey (Unted Kingdoml: Paul E. Jessop, MoMaster Univ. (Canada): Lynda K. Rowe, Carteton Unv (Canada): Sarah M. Mofaul, Doug M. Bruce, MoMaster Unw (Canada) N. Garry Tarr, Carloton Unw (Canada) ......................... [6898-23] Cotbe Break............10:10 to 10:30 am

\section{SESSION 8}

Room: Conv. Cir. A1 . . ............. Wed. 10:30 am 10 12:10 pm

\section{Waveguides II}

Session Chair: Andrew W. Poon, Hong Kong Univ. of Science and Technology (Hong Kong China)

10.30 an: Fiber on a chip: noninear optics for data communication via silicon photonic wires (Inwited Paper), Richard M. Osgood, Jr, Xaogang Chen Wel Hsieh, Jerry I. Dadap, Jr. Nicolae C. Panoiu, Columbia Univ.; Wiliam M J.Green, Yurii G. A. Vlasov, IBM Thomas J. Watson Reseatch Ctr. ... [6898-24]

$11: 10 \mathrm{am}$ Silicon waveguides for the mid-infrared wavelength region, Goran Z. Mashanovich, Pengyuan Yang, Univ, of Surrey (United Kingdom); Stevan Stankovic, Univ. of Belgrade (Serbia and Montenegro): Ee Jin Teo, National Univ. of Singapore (Singapore); Jasna V. Crnjanski, Univ of Betgrade (Serbia and Montenegro); Georg Pucker, Fondazione Bruno Kessler (ttaly); William R. Headley III, Univ. of Surrey (United Kingdom); Andrew A. Bettiof, Mark B. H. Breese, National Univ of Singapore (Singapore): Graham T Reed Univ of Surrey (United Kingdom) . . . . . . . . . . . . . . . . . . . . . . . . . . . . [6898-25] 11,30 am: Leakage studies on Sol slot waveguide structures. PaLl Mülner Norman Finger, Rainer Hainberger, ARC Seibersdorf Research GmbH (Austria) . . . . . . . . . . . . . . . . . . . . . . . . . $66898-26]$

11.50 am: Low-temperature amorphous siticon based photonic crysta technology, Khadijeh Bayat, Sujeet K. Chaudhuri, Saffiedin Safavi-Naeni, Univ. of Watenoo (Canada). . . . . . . . . . . . . . . . . . . . . . . . . . . $6898-27$ Lunch/Exhibition Break . . . . . . . . . . . . . . . . . . . 12:10 to 1:30 pn

\section{SESSION 9}

Room: Conv. Gtr. A1 ..................Wed.

Waveguides III

Session Chair: L. W. Cahil, La Trobe Univ. (Australia)

1:30 pm: Silicon microsphere photonics, All Serpenguzel, Koc Univ.

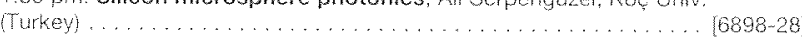
1:50 pm: Opticat solitons in a silicon waveguide, Jidong Zhang. Qlang Lin, Giovann Piredda, Robert W. Boyd, Govind P. Agrawal, Philippe M. Fatchet, Univ of Rochester............................. [6898-29]

2:10 pm: Nonlinear optics in silicon-polymer systems, Michael Hochbero Calfornia Institute of Technology and Univ. of Washington; Tom W. BaehrJones, Guangx Wang. Axel Scherer, Calfomia institute of Technologyl6898-30] 230 pm: Vertically integrated multimode interterometers for 30 photonic circuits in Sol. Chris J. Brooks, Andrew P. Knights, Paul E. Jessop, MoMasier Univ (Canada).............................. [6898-31] 2.50 pm: Experimental demonstration of waveguide-coupled comer-cut square resonators, Elton Marchena, Shouyuan Shi, Denns W. Prather. Uhiv. of

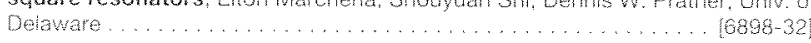

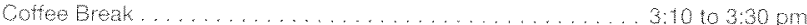




\section{:}

\section{opto 2008 plenary Session}

Session Chairs: Ali Adbi, Georgle hsthte of Technology: James G. Grote, Air Force Fesearch Lab.

Boom: Conv. Cir. A7/A8-8:30 to $10.00 \mathrm{am}$

830 am htroduction and Opening Remanks

8:40 am: Nanophotonics: from Photonic Crystals to Plasmonics

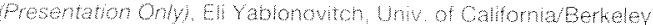

920 an: Organic "Plastic" Optoelectronic Devices (Presentation Only. Nyazi Serdar Sarichtol Jonames Kepler Univ. Lnz (Austria)

$$
\text { Seep. } 20 \text { for detals. }
$$

Cotee Breat 10,00101030 am

SESSION

Room: Conv. Chr. B4 ............ Tues. 10:30 am to $12: 20 \mathrm{pm}$

THz Lasers

Session Chair: Dan Botez, Univ. of Wisconsin/Madison

$10: 30$ am: High-temperature and high-power operation of terahert quantum-cascade lasers finvited Papen Stishil Kumar, Alan W Lee O Oin, Massachusetts institute of Technology. Beniamin S. Williams, Univ. of Calitornia/Los Angeles; Ong Hiu, Massachusets institute of Technology: John

L. Reno, Sandia National Labs...................... [6909-17]

11:00 am: Progress in quantum cascade lasers (hvited Papen, Jerome Fatst ETH Zurich Swizenland . . . . . . . . . . . . . . . . . . . . . . $16909-18$

1130 am: Teraheriz source based on intracavity difference-frequency Generation in quantum cascade lasers thowted Paper Mikhail A. Bekin. warvard thiv A A

resolvedinvestigation of heat-iransport d6909-19]

12:00 pm: Time-resolved investigation of heat-iransport dynamics in $\mathrm{THZ}$ quantum-cascade fasers, Miriam Serena Vhtelo. Vincenzo Soagnoio Gaetano

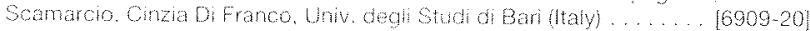

\section{SESSION 6}

Room: Conv. Ctr. A1 .................. Tues. 1:30 to $3: 30 \mathrm{~mm}$ Silicon Photonics !

Joint Sesson with Conterene 6898 : Smon Photonics II

130 pm A monolithic integrated low-theshold Raman silicon laser

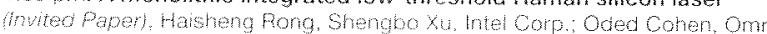

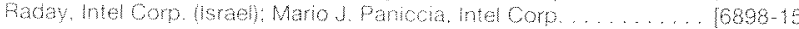
200 pm: Slicon nanocrystals and Er coupled to silicon nanochstais for lasers and amplifiers (hvited papen, Nowd Daldosso, Lorenzo Puvesi. Zeno

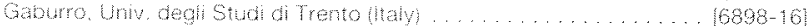

290 pm: Monohthicaly integrated W-Sb dode lasers on miscut 5

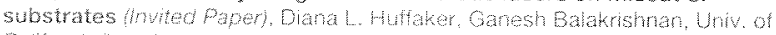

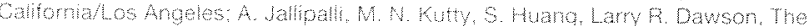

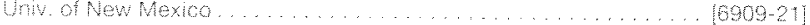

300 pm On-cho integration of quantum dot lasers with waveguides and

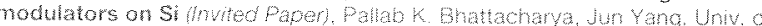
Mohloan $[6909-22]$

chee Brea 3,30 to $400 \mathrm{~mm}$
SESSION 7

Room: Conv. Cr. A1 ................ Tues. 4.00 to $5: 30$ om Silicon Photonics

Jom Sesson with Conterence 6898: Slloon Fhotonics $\mathrm{II}$

$4,00 \mathrm{pm}$. Electrically injected inP microdisk lasers integrated with nariophotonic Sol circults (mited Paper), Joris Van Campenhout Univ Gent (Belgum), Pedro Rojo-Romeo, Phinope Regreny, Christian Seassat. Ecole Centrale de Lyon (France); Dries Van Thouthout, Univ Gent (Betgium; Lea Di Cioccio, Commissariat a Phergie Atomique (France), Chrystelle Lagahem Blanchard, TRACIT Technologies (France); Jean-Marc Fedeli, Commissariat à "Energie Atomique (France); Roel G. Baets, Univ. Gent (Belgum). . . [6898-17] $4: 30$ pm: Recess integration of micro-cleaved laser diode platelets with dielectric waveguides on silicon (invited Papen), Clifton $G$. Fonstad, Jr., Joseph Rumpler, Edward Barkley, Shaya Famenini, James Perkins, Massachusets Institute of Technology. ................. [6909.23] $5.00 \mathrm{pm}$ : Integrated AlGainAs-silicon evanescent racetrack laser and photodetector (hvited Paper), Alexander W. Fang. Univ. of Californa/Santa Barbara: Richard Jones, Intel Corp. Hyundai Park, Univ. of California/Santa Garbara; Oded Cohen, Omri Raday, Intel Corp. (Israen); Mario J. Paniccia Inte Comp; Jom E. Bowers, Univ of Calfomia/Santa Barbara . . . . . . . [6898-18|

\section{Medrescley 23 dantary}

\section{SESSION 8}

Room: Conv. Ctr. B4 .................Wed. $8: 10$ to $10: 00$ an

\section{High Brightness}

Session Chair: Gary A. Evars, Photodigm inc.

8:10 am: High-brightness diode lasers with very narrow divergence (Irvited Paper), Gotz Erbert, Frank Bugge, Joerg Fricke, Karl-Heinz Hasler. Hans Wenzel. Guenther Traenkle, Ferdinand-Braun-Institut für Höchstfrequenztechnik (Germany) $[690924$

8:40 am: Highly reliable, high-brightness 915 -nm laser diodes for fiber lase applications, Zuntu Xu. Wei Gao, Lisen Cheng. Keilan Luo, Kun Shen, Andre Mastrovito, Axcel Photonics, inc ..................... [6909-25 9.00 am: Asymmetric Al-free active-region laser structure for highbrightness tapered lasers at $975 \mathrm{~nm}$, Nicolas Michel, Michel Lecomte, Olvier Parllaud, Michel M. Krakowski, Thales Research \& Technology (France) JoseMantel Garcia-Tíero, Ignacio Esquivias. Univ. Politécnica de Madrid (Spain)................................. [6909-26] 9:20 am: High-reliability, high-power arrays of 808-nm single-mode diodelasers employing various quantum well structures. Bocang Qiu, Olek. P. Kowalski. Stewart $\mathrm{O}$. MoUougall Xuefeng Lu, John H. Marsh, Intense Ltd. (United Kingdom. . . . . . . . . . . . . . . . . . . . . . . [6909-27] $9: 40$ am: Grazing incidence slab semiconductor laser (GAISSL). Anish K Goyal, Robin K. Htiang, Leo J. Missaggia, MT Uncon Lab. . . . . . . . 6909-28] Cotee Break............................ 1000 to $10.30 \mathrm{am}$ SESSION 9

Boom: Comv. Ct. B4 . . . . . . . . . . Wed. 10:30 am to 12:20 pm Mid-IR Lasers

Session Chair: Ciatre F. Gmach, Princeton Univ.

10.30 am: InAs-based quantum-cascadelasers (nvited Paper), Alexei $N$ Baranov, Roland Teissier, Jan Deverson, Oliver Cathabard, Unis. Montpeller II

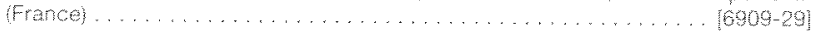

1 too am, Short-wavelengh quantum cascade lasers (invited Prper, John

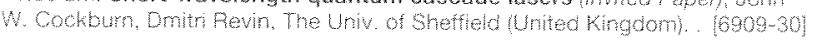

1130 am Fiber-coupled, Gasb-based dode-laser modules for the $2 \times$ Wham wavelength range. Chrstan Mam, Marcel Patunce. Eva Ceemos.

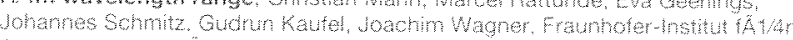

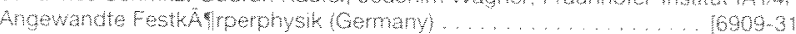

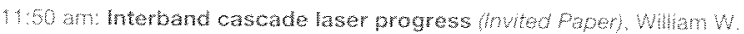

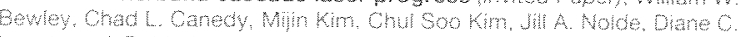

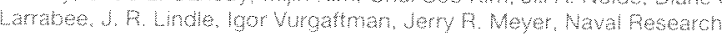
Lebs

Unchexhwhon Brok $122010103 \mathrm{~mm}$ 

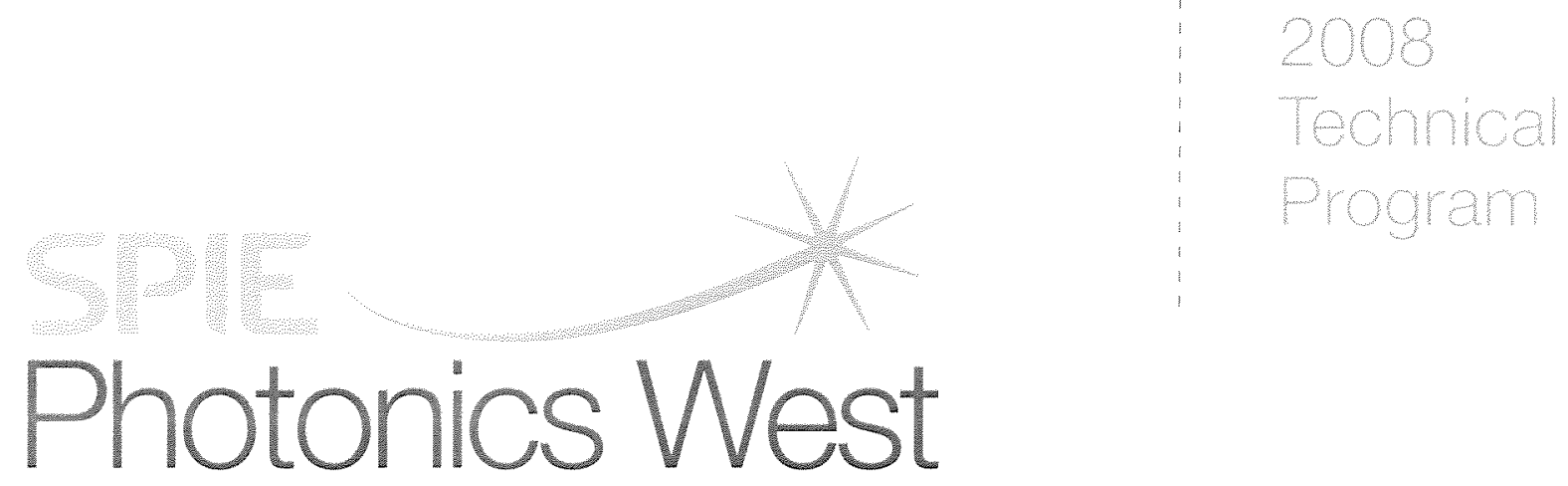

Conferences + Courses: 19-24 January 2008

Biomedical Optics Exhibition: 19-20 January 2008

Photonics West Exhibition: 22-24 January 2008

San Jose Convention Center

San Jose, California USA
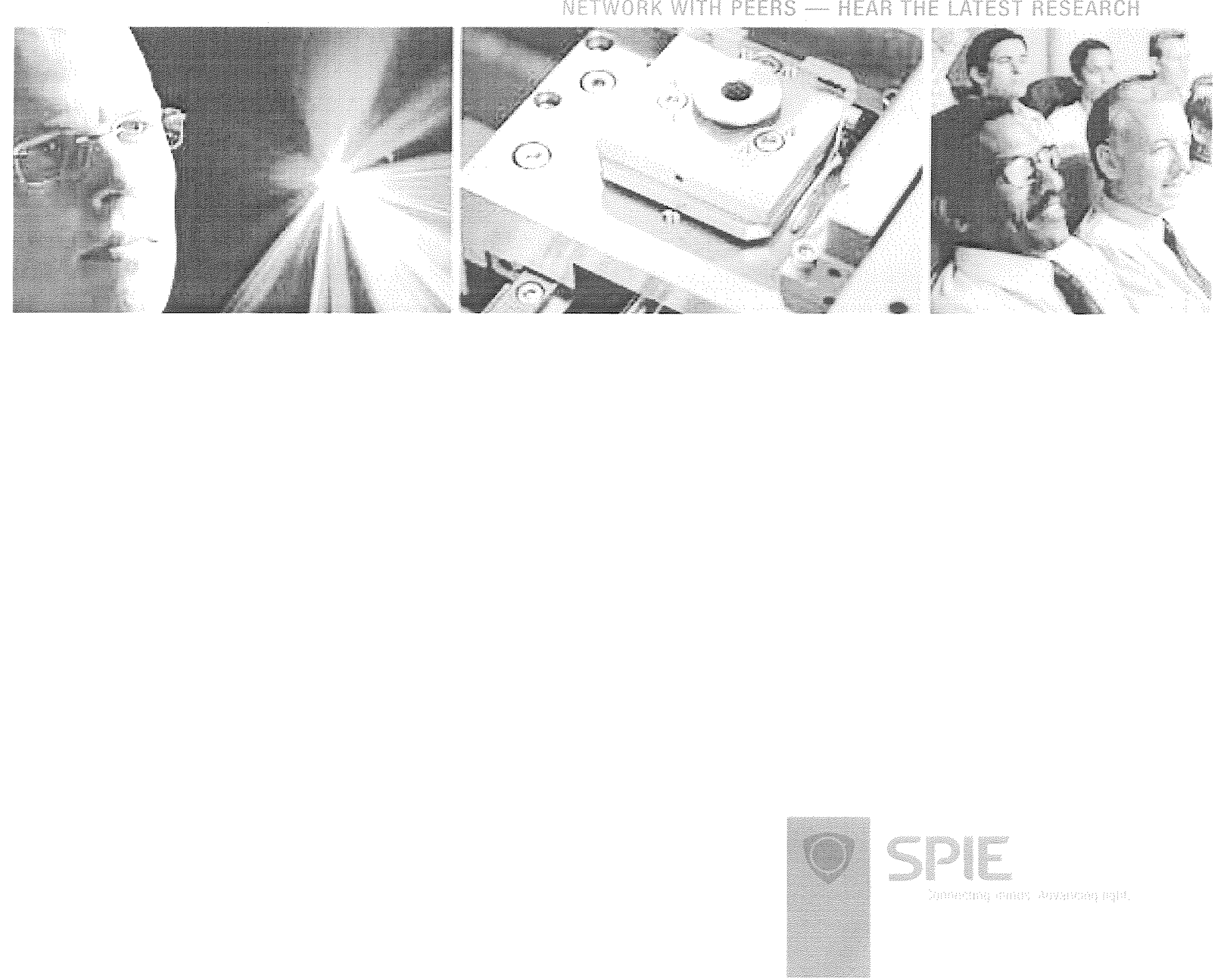